\title{
Effect of Letrozole on sperm parameters, chromatin status and ROS level in idiopathic Oligo/Astheno/Teratozoospermia
}

\author{
Leila Kooshesh $^{1 \dagger}$, Soghra Bahmanpour ${ }^{1 \dagger}$, Shahriar Zeighami ${ }^{2}$ and Mohammad Hussain Nasr-Esfahani $i^{3,4^{*}}$
}

\begin{abstract}
Background: This study investigates the effect of letrozole on hormone profiles, semen parameters, body mass index (BMI), degree of oxidative stress and sperm chromatin integrity in men with idiopathic oligo/astheno/ teratozoospermia (iOAT) and $\mathrm{T}: \mathrm{E}_{2}$ ratio $\leq 10$.
\end{abstract}

Materials and methods: This study is a longitudinal, prospective, interventional and open-labelled clinical trial. Semen samples were collected from 20 iOAT men with low serum testosterone (T) to estradiol $\left(E_{2}\right)$ ratio $\left(T: E_{2}\right.$ ratio $\left.\leq 10\right)$. The participants were treated with $2.5 \mathrm{mg}$ letrozole orally per day for 3 months. Then, sperm parameters, hormone profiles, BMI, chromatin integrity and intracellular reactive oxygen species (ROS) level were assessed pre- and post- treatment. The chromatin integrity was evaluated by assessment of DNA fragmentation (with TUNEL assay) and protamine deficiency (with Chromomycin A3, CMA3). Also, the intracellular ROS levels were investigated by 2', 7'-dichlorodihydrofluorescein diacetate (DCFH-DA) staining. Finally, the differences between the parameters evaluated before and after letrozole treatment were analyzed with the t-test and the Wilcoxon signed-rank test.

Results: Sperm concentration, percentage of sperm motility and its normal morphology increased significantly after letrozole treatment. Moreover, serum testosterone level increased but estradiol level decreased significantly following treatment. The mean of T:E2 ratio improved $1600 \%$. Also, letrozole treatment significantly reduced the percentage of sperm TUNEL positivity and sperm CMA3 positivity. While no significant difference was observed between intracellular ROS levels and BMI before and after treatment. Finally, as a notable result, four spontaneous pregnancies (20\%) were achieved after treatment.

Conclusions: Letrozole treatment can effectively increase spontaneous pregnancies by improving sperm parameters and sperm chromatin integrity in men with iOAT and T:E2 ratio $\leq 10$.

Trial registration: Trial registration: IRCT, IRCT20191030045283N1. Registered 16 November 2019 - Retrospectively registered, https://fa.irct.ir/user/trial/43484/view

Keywords: Letrozole, Idiopathic oligo/astheno/teratozoospermia, Hormonal profile, Sperm DNA fragmentation, ROS, Protamine deficiency

\footnotetext{
* Correspondence: mh.nasr-esfahani@royaninstitute.org

†Leila Kooshesh and Soghra Bahmanpour contributed equally to this work.

${ }^{3}$ Department of Reproductive Biotechnology, Reproductive Biomedicine

Research Centre, Royan Institute for Biotechnology, ACECR, Isfahan, Iran

${ }^{4}$ Isfahan Fertility and Infertility Centre, Isfahan, Iran

Full list of author information is available at the end of the article
}

(c) The Author(s). 2020 Open Access This article is licensed under a Creative Commons Attribution 4.0 International License, which permits use, sharing, adaptation, distribution and reproduction in any medium or format, as long as you give appropriate credit to the original author(s) and the source, provide a link to the Creative Commons licence, and indicate if changes were made. The images or other third party material in this article are included in the article's Creative Commons licence, unless indicated otherwise in a credit line to the material. If material is not included in the article's Creative Commons licence and your intended use is not permitted by statutory regulation or exceeds the permitted use, you will need to obtain permission directly from the copyright holder. To view a copy of this licence, visit http://creativecommons.org/licenses/by/4.0/ The Creative Commons Public Domain Dedication waiver (http://creativecommons.org/publicdomain/zero/1.0/) applies to the data made available in this article, unless otherwise stated in a credit line to the data. 


\section{Background}

The mechanisms associated with idiopathic male infertility, mostly iOAT, are not fully known and need further investigation [1-3]. A number of factors may be involved in the genesis of this condition, including age [4], non-inflammatory alterations in the function of post testicular organs like prostate [5, 6], infective agents [7], environmental disturbances $[8,9]$, subtle hormonal anomalies and genetic and epigenetic factors [8]. Considering these probable etiologies, opportunities have been provided for further research in new approaches of empirical medical therapy.

Based on the understanding of hormonal control of spermatogenesis, several medications such as gonadotropins, androgens, estrogen receptor blockers (clomiphene and tamoxifen citrate), and aromatase inhibitors as empirical treatments are used for idiopathic male infertility [1013]. The hormonal profile of men with iOAT has demonstrated lower serum testosterone level, higher serum estradiol level, and therefore, lower T:E2 ratio than normal men [8]. In addition, a research has shown that the mean of $\mathrm{T}(\mathrm{ng} / \mathrm{dl}): \mathrm{E}_{2}(\mathrm{pg} / \mathrm{ml})$ in men with severe infertility and normal conditions is 6.9 and 14.5, respectively. According to this research, a cut-off point 10 was proposed as the lower limit of the T: E2 ratio for normal men [14]. Therefore, based on such observations, aromatase inhibitors (especially letrozole) have gained much attention for the treatment of iOAT with $\mathrm{T}: \mathrm{E}_{2}$ ratio $\leq 10$ [15-19].

Letrozole as an aromatase inhibitor has been widely used in the treatment of female infertility [20-22]. There are limited studies that have evaluated the therapeutic potential of letrozole in male infertility [15-19]. Letrozole is a selective and highly potent aromatase inhibitor that inhibits the enzyme activity of intracellular aromatase. Therefore, it can reduces the conversion of testosterone to estradiol and androstenedione to estrone [23]. Inhibiting estrogen production can reduce the negative feedback on the hypothalamus-pituitary axis, resulting in increase of FSH and LH (luteinizing hormone) levels which, in turn, can increase testosterone and stimulate spermatogenesis [23, 24].

There is a positive relationship between letrozole and improvement of sperm concentration, percentage of sperm motility and morphology [15-19]. But regarding to our information, there is no research about the effect of letrozole on sperm functional characteristics, while the sperm DNA constitute approximately $50 \%$ of the future progeny DNA, and chromatin anomalies have a negative impact on fertilization rate, embryo development, live birth and abortion rate [25-33]. Therefore, the aim of this study is investigating the effect of letrozole on hormone profiles, conventional semen analysis, BMI, the degree of oxidative stress and sperm chromatin integrity in men with iOAT and T:E2 ratio $\leq 10$.

\section{Materials and methods}

\section{Patients selection}

This study is a longitudinal, prospective, interventional and open-labelled clinical trial (Trial Registration: IRCT20191030045283N1, Registered 16 November 2019) and has received the approval of the Ethical Board of Shiraz University of Medical Sciences (IR.SUMS.REC.1397.273). During 2018 and 2019, the patients with iOAT and a serum T:E2 ratio of $\leq 10$ [15-19], referred to male infertility clinics affiliated with Shiraz University of Medical Sciences, were considered as candidates for inclusion in our study. Individuals with leukocytospermia (more than $1 \mathrm{million} / \mathrm{ml}$ ), tobacco or alcohol abuse, ongoing medical treatment (gonadotropins, anabolic steroids, non-steroids anti-inflammatory drugs and cancer chemotherapy), previous cancer radiotherapy or chemotherapy, varicocele and Klinefelter syndrome were excluded in this study [18]. Also, the candidates that their female partners had a history of gynecological problems were excluded from the research [19]. A total of 20 eligible males with mean age of 34.9 years old, ranging from 24 to 43 years, were recruited in this study and all of them finished the study correctly. Also, the participants were informed about the study objectives and signed an informed consent form.

All the participants were orally treated with $2.5 \mathrm{mg}$ letrozole (Soha Pharma Company, Iran) per day for 3 months [15-18]. Semen parameters, sperm chromatin integrity, intracellular ROS level and BMI was evaluated before and after letrozole administration, and also serum testosterone and estradiol levels were measured at the end of treatment.

\section{Semen sample}

Semen samples were provided by masturbation following 3-5 days of sexual abstinence before and after 3 months of letrozole administration. A proportion of each semen sample was analyzed according to the World Health Organization guidelines (WHO, 2010) [34]. The remaining semen samples were used for the analysis of sperm DNA fragmentation by TUNEL assay, sperm protamine deficiency by CMA3 staining and sperm intracellular ROS level by DCFH staining. If the sample was not enough to carry out all these tests, a second semen sample was provided by the participant after 3-5 days of sexual abstinence.

\section{Assessment of sperm protamine deficiency}

In this study, protamine deficiency was assessed by Chromomycin A3 (CMA3). The CMA3 competes with protamine, the main protein involved in sperm DNA packaging, for binding to small grooves and guanine and cytosine-rich regions of DNA. Therefore, the percentage of CMA3 staining correlates inversely with the protamination status, and indirectly assesses the degree of protamine 
deficiency $[35,36]$. For this purpose, after washing the semen samples with phosphate-buffered saline (PBS) free of $\mathrm{Ca}^{2+}$ and $\mathrm{Mg}^{2+}$, the samples were fixed with carnoy's solution (methanol: glacial acetic acid 3:1) for five minutes at $4{ }^{\circ} \mathrm{C}$. The prepared smears were stained for $20 \mathrm{~min}$ with $100 \mu \mathrm{l}$ of $\mathrm{CMA}_{3}$ solution $\left(25 \mathrm{mg} / \mathrm{ml} \mathrm{CMA}_{3}\right.$ in a buffer called Mcllvaine $[7 \mathrm{ml}$ citric acid $(0.1 \mathrm{mmol} / \mathrm{l}), 32.9 \mathrm{ml}$ $\mathrm{Na}_{2} \mathrm{HPO}_{4}, \quad 7 \mathrm{H}_{2} \mathrm{O} \quad(0.2 \mathrm{mmol} / \mathrm{l}), \quad$ PH $\quad 7.0$ containing $\left.\left.10 \mu \mathrm{mol} / 1 \mathrm{MgCl}_{2}\right)\right]$ ). Subsequently, each smear was rinsed in the same buffer and mounted with buffered glycerol [1]. Olympus fluorescence microscope (BX61, Tokyo, Japan) with the appropriate filters $(460-470 \mathrm{~nm})$ was used for analysis. For each participant, 200 spermatozoa were assessed. The CMA3 positive sperm was distinguished from the CMA3 negative one through its bright yellow staining [35].

\section{Assessment of sperm DNA fragmentation}

In our study, for assessment of sperm DNA fragmentation, terminal deoxynucleotidyl transferase-mediated fluorescein-dUTP nick end labeling (TUNEL) assay was carried out by Promega DeadEnd ${ }^{\mathrm{m}}$ Fluorometric TUNEL kit. In this assay, single and double DNA strand breaks at the $3{ }^{\prime} \mathrm{OH}$ ends are labeled by fluorescent dUTP nucleotides using the template and primer independent TdT (terminal deoxynucleotidyl transferase) and then fluorescence is detected by flow cytometry [37]. In this study according to the kit manufacturer instructions, a minimum of $3 \times 10^{6}$ sperm cells from each semen sample were washed twice in PBS and fixed by $8 \%$ paraformaldehyde for $25 \mathrm{~min}$ at room temperature. The cells were then Permeabilized by $0.4 \%$ Triton X-100 solution and equilibrated with equilibration Buffer for $7 \mathrm{~min}$ at room temperature. After washing, the cells were incubated for $60 \mathrm{~min}$ at $37^{\circ} \mathrm{C}$ in the DNA-labeling solution (including Nucleotide Mix and TdT). Along with the test sample, analysis was also done for negative control sample. The negative control sample was prepared by DNA-labeling solution without TdT enzyme. Finally, test and negative control samples were washed twice in PBS and diluted to a final volume of $300 \mu \mathrm{l}$ in PBS.

After preparation of samples, the fluorescent was detected by flow cytometer (FACS calibur flow cytometer; Becton Dickinson san Jose CA, USA) and the obtained data were then analyzed using the flowjo software (Version 7.6).

\section{Assessment of sperm intracellular ROS level}

Intracellular ROS level was measured using a flowcytometry based DCFH-DA staining. DCFH-DA, a nonfluorescent probe, can pass the cell membrane. In the cell, DCFH-DA is deacetylated to DCFH by cellular esterase. DCFH is another non-fluorescent probe that cannot cross the cell membrane. DCFH reacts with $\mathrm{H}_{2} \mathrm{O}_{2}$ (an intracellular ROS) to form DCF that is a fluorescent probe and can be detected by flow cytometry [38, 39].

For this assay, a sperm suspension (including $2 \times 10^{6}$ sperm $/ \mathrm{ml}$ in PBS) was exposed to $0.5 \mu \mathrm{m}$ DCFH- DA and incubated at $37^{\circ} \mathrm{C}$ for $30 \mathrm{~min}$. Along with the test sample, a negative control sample was prepared only by PBS. Samples were then washed twice in PBS. Finally, the samples were diluted to a final volume of $400 \mu \mathrm{l}$ PBS and analyzed by flow cytometry $[38,40]$. Flow cytometry data were then analyzed using the flowjo software (Version 7.6).

\section{Statistical analysis}

Statistical analysis was performed by the prism and SPSS software. The population normality was verified with the D'Agostino-Pearson omnibus test. The differences between the assessed parameters before and after letrozole treatment were evaluated with the $t$-test for the paired samples or the Wilcoxon signed-rank test, depending on the distribution of the parameters. Associations among quantitative parameters were analyzed by the Spearman correlation coefficient. Results are presented as mean \pm SEM (Standard Error of Mean). Probability value of less than 0.05 was considered to be statistically significant.

\section{Results}

In this study, 20 participants with iOAT and serum $\mathrm{T}: \mathrm{E}_{2}$ ratio $\leq 10$ were treated with letrozole for 3 months. These infertile men were evaluated for semen parameters, hormone profiles, BMI, sperm DNA fragmentation, protamine deficiency and sperm intracellular ROS level pre-and post-treatment. No severe side-effects were reported during the treatment, only five patients declared the reduction of their libido. Also, following letrozole administration, four spontaneous pregnancies (20\%) were reported.

\section{Effect of letrozole on hormone profiles, semen parameters and BMI}

Figure 1a-c compare hormone profiles before and after 3 months of letrozole administration. The results of Fig. 1ab show that the mean of serum testosterone level (ng/dl) increased significantly ( $351.7 \pm 32.85$ versus $899.3 \pm 108.7$; $P=0.0001$ ), and conversely, the mean of serum estradiol level $(\mathrm{pg} / \mathrm{ml})$ decreased significantly $(80.29 \pm 10.9$ versus $12.79 \pm 1.31 ; P<0.0001)$ after the administration of letrozole. In all patients, the $\mathrm{T}: \mathrm{E}_{2}$ ratio increased significantly $(5.23 \pm 0.61$ versus $84.69 \pm 12.03 ; P<0.0001)$ after 3 months of letrozole treatment (Fig. 1c).

Figures 2a-d compare sperm parameters before and after 3 months of letrozole administration. The mean of sperm concentration $\left(10^{6} / \mathrm{ml}\right)$ increased significantly $(8.565 \pm 1.13$ versus $30.93 \pm 4.36 ; P<0.0001)$ following treatment (Fig. 2a). The mean of sperm motility percentage increased significantly $(22.95 \pm 4.63$ versus $37 \pm 5.48$; 


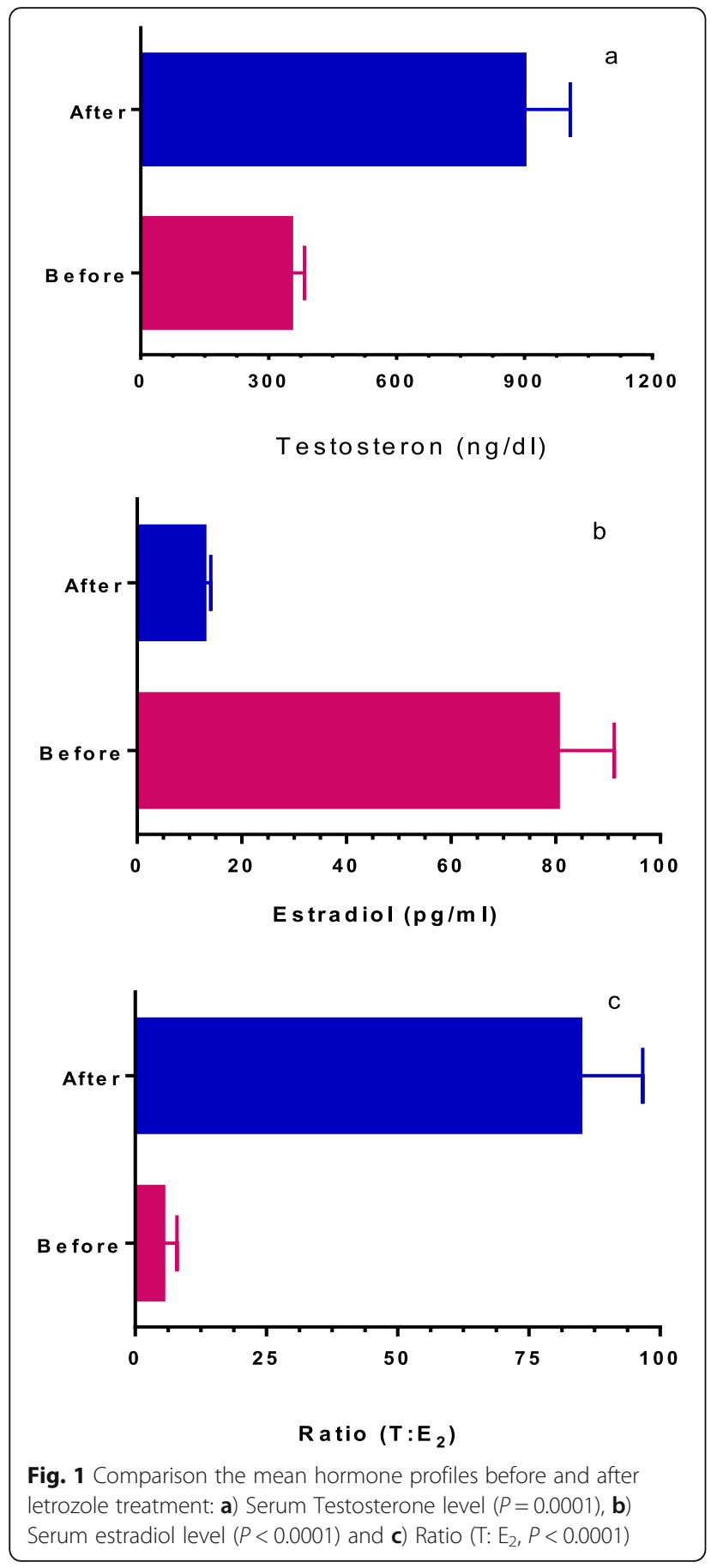

$P=0.035)$ after letrozole treatment (Fig. 2b). Also, the mean of normal sperm morphology percentage increased significantly $(0.925 \pm 0.34$ versus $3.175 \pm 0.57 ; P<0.0001)$ following letrozole administration (Fig. 2c). There is no significant difference between the mean ejaculation volume (ml), $(2.85 \pm 0.27$ versus $3.16 \pm 0.23 ; P=0.299)$, before and after letrozole treatment (Fig. 2d).

There is also no significant difference between the mean BMI $\left(\mathrm{kg} / \mathrm{m}^{2}\right)$ from pre-treatment to post-treatment
( $29.81 \pm 3.63$ versus $30.04 \pm 3.52$ ). Moreover, no significant correlation was observed between the baseline BMI and improvement of sperm parameters, hormonal balance, chromatin status and the intracellular ROS level following the administration of letrozole.

\section{Effect of letrozole on the sperm chromatin status and the} intracellular ROS level

In this study, in order to assess the chromatin status, sperm DNA fragmentation and protamine deficiency were evaluated by TUNEL and CMA3 staining, respectively. Further, the intracellular ROS levels were assessed by DCFH-DA staining.

Figure 3 compares flow cytometry analysis of sperm TUNEL positivity percentage obtained from $\mathrm{IOAT}$ men with $\mathrm{T}: \mathrm{E}_{2}$ ratio $\leq 10$, before and after letrozole treatment. Also Fig. $4 \mathrm{a}$ indicates that the mean of sperm TUNEL positivity percentage decreased significantly $(14.75 \pm 3.29$ versus $9.28 \pm$ 2.04; $P=0.0401$ ) after 3 months of letrozole administration.

The mean of sperm CMA3 positivity percentage decreased significantly $(43.12 \pm 2.91$ versus $31.12 \pm 2.46 ; P=$ 0.0001) after treatment (Fig. 4b). Moreover, there is a significant correlation between the percentage of sperm CMA3 positivity and sperm DNA fragmentation $(\mathrm{r}=+$ $0.832, P<0.001$ ).

Figure 5 indicates the mean sperm DCF positivity reduced after letrozole treatment $(11.66 \pm 2.52$ versus $9.4 \pm 2.36$; $P=0.261$ ), but this reduction was not statistically significant.

\section{Discussion}

The results of this study showed that letrozole increases the serum testosterone levels and decreases the serum estradiol levels in iOAT individuals with $\mathrm{T}: \mathrm{E}_{2}$ ratio $\leq 10$, significantly, (Fig. 1a-b). It is interesting to note that the $\mathrm{T}: \mathrm{E}_{2}$ ratio increased to higher than 10 (Fig. 1c) and this ratio improved $1600 \%$ after letrozole treatment. These results are consistent with the previous reports [15-19].

In men, the main source of estrogen is from the conversion of testosterone to estradiol catalyzed by the aromatase enzyme in the endoplasmic reticulum of testicular Leydig cells [41]. Estrogen has a strong negative feedback on the hypothalamus pituitary axis and can decrease the production and release of FSH and LH [24]. In the male reproductive system, inhibition of estrogen production by aromatase inhibitor, can increase FSH and LH levels, which, in turn, increase the intratesticular testosterone level and improve spermatogenesis [23]. Therefore, the hormonal balance created following letrozole administration, may be related to this inhibitory effect. This effect is probably due to aromatase inhibition in the testicular Leydig cells, which limits estrogen production, and thereby maintains testosterone level [42]. In addition, estrogen has direct and adverse effects on testicular germinal epithelium [43]; hence, the 


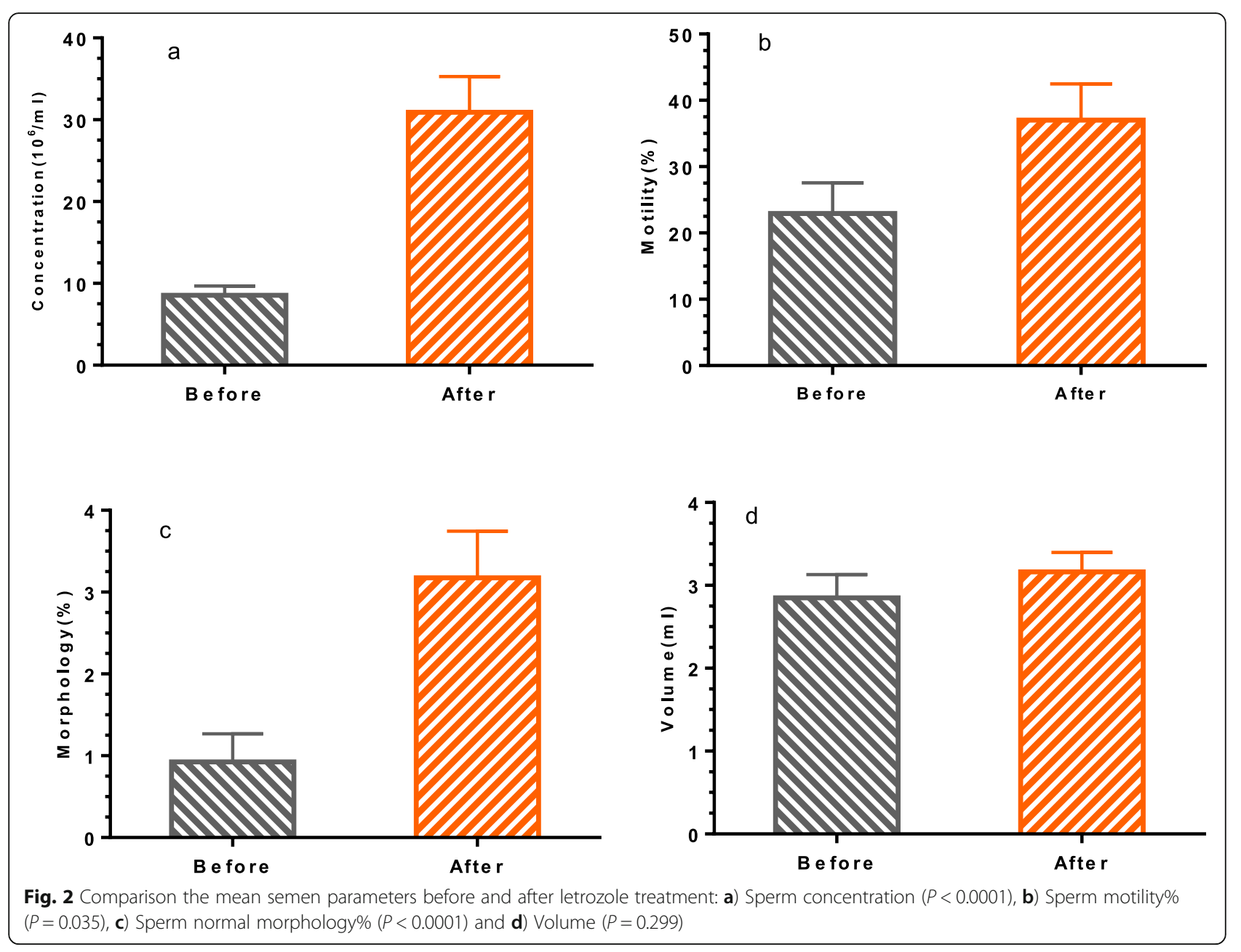

low T:E2 ratio may be responsible for impaired spermatogenesis, which can reverse by letrozole. One of the shortcomings of this study is that FSH and LH were not measured in parallel with estrogen and testosterone hormones.

Our results showed that sperm concentration, sperm motility and sperm morphology improved 260, 61 and $240 \%$, respectively after letrozole treatment (Fig. 2a-c). These results are consistent with Previous studies [15-19]. This improvement in sperm parameters is due to the hormonal balance induced by letrozole through the inhibition of estradiol and increase of FSH and testosterone levels as markers of spermatogenesis and Sertoli cell function.

In Fig. 5 it was indicated that the degree of ROS reduced after letrozole treatment, but this reduction was not statistically significant. This is probably related to our inclusion criteria, because individuals at high risk of oxidative stress were not included in our study. Previous studies have shown that ROS levels in infertile men are higher than normal men [44]. ROS negatively affects the hypothalamus pituitary axis and decreases LH and FSH secretion, which, in turn, decrease the intratesticular testosterone level [45]. On the other hand, ROS can raise aromatase activity, which results in more $\mathrm{E}_{2}$ production and the inhibition of testosterone release [45]. It seems that, increased $\mathrm{E}_{2}$ in iOAT patients with $\mathrm{T}: \mathrm{E}_{2}$ ratio $\leq 10$ is likely to be related to high ROS level. Nonetheless, further research is required to evaluate this hypothesis. It is also important to note that, testosterone has antioxidant activity [45], and high level of estrogen can, inversely, suppress the expression of antioxidant enzyme [46]. Therefore, decrease of ROS level in our study may be related to the hormonal balance created in patients.

One of the important and essential elements involved in proper sperm formation during spermiogenesis is the proper replacement of histone with protamine [47-49]. The results of our study showed that the degree of protamine deficiency, assessed by CMA3 staining, decreased significantly after letrozole administration, (Fig. 4b). Researches have shown that protamine deficiency makes the sperm prone to DNA fragmentation [47-49]. Consequently, we also assessed DNA integrity through the TUNEL assay. The results of this assessment revealed that the degree of DNA fragmentation was lower after letrozole administration (Fig. 4a). 


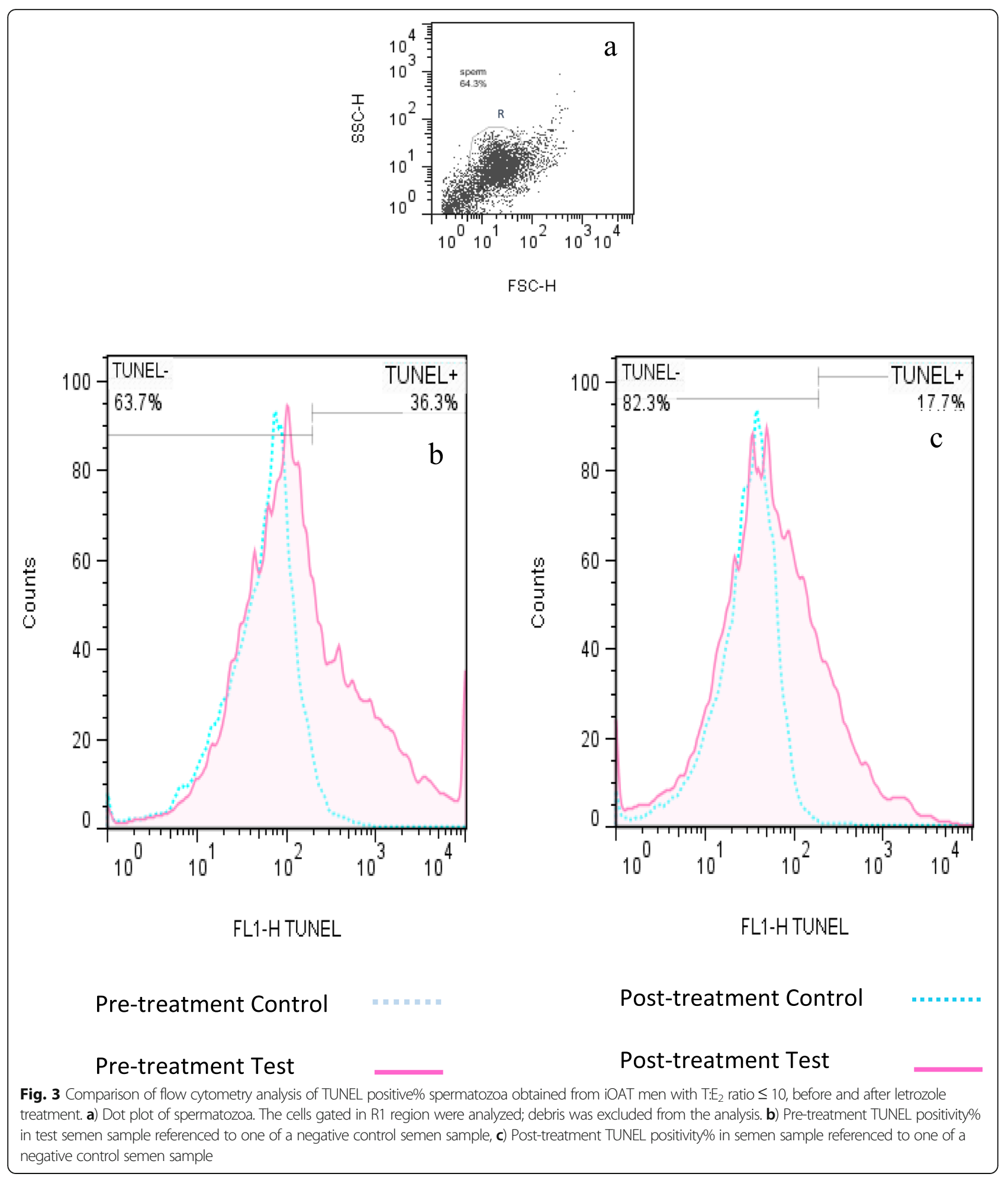

Three mechanisms that account for DNA fragmentation include: 1) defective chromatin packaging due to endogenous nuclease (topoisomerase II) inactivity to re-ligate the nicks during spermiogenesis, 2) abortive apoptosis and 3) DNA damage due to oxidative stress during the epididymal passage when mitochondria becomes active for ATP production during maturation in epididymis [50-53] . Considering that, we did not observed a significant decrease in ROS production, the improvement of DNA fragmentation is probably related to improved chromatin packaging and 

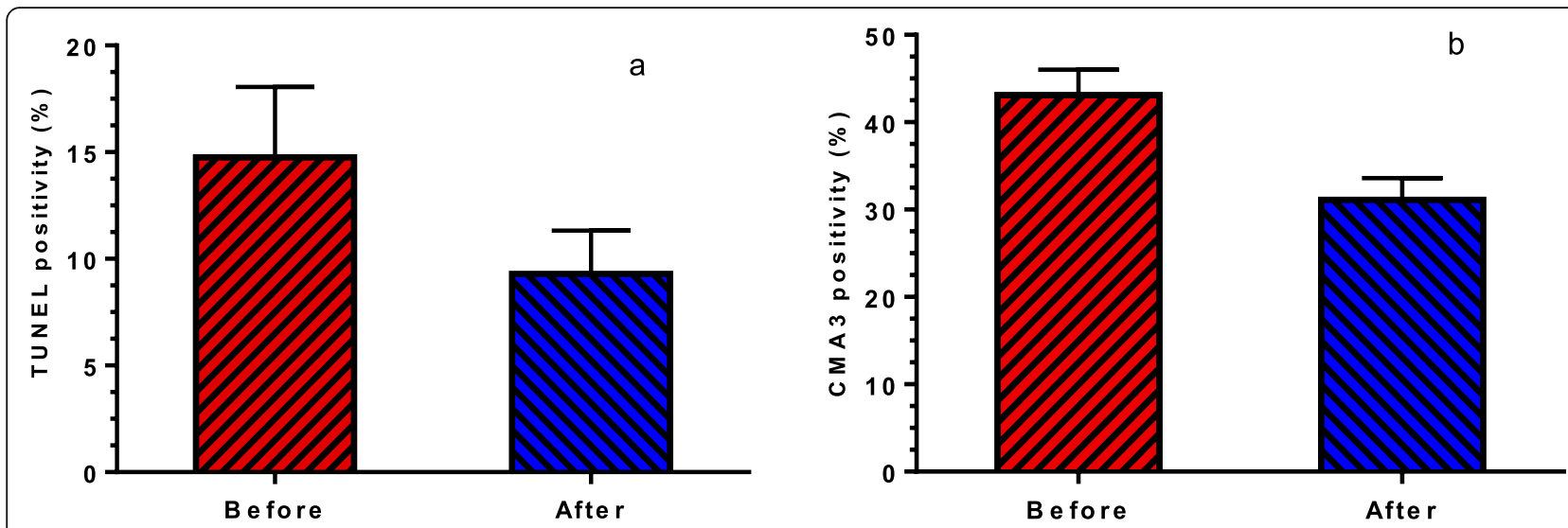

Fig. 4 Comparison a) The mean sperm DNA fragmentation percentage (TUNEL positivity $\%, P=0.0401$ ) and $\mathbf{b}$ ) The mean sperm protamine deficiency (CMA3 positivity\%, $P=0.0001$ ), before and after letrozole treatment

apoptotic pathway,which are mainly dependent on the levels of sex hormones [54]. Indeed, several studies have revealed that hormonal imbalance, altered FSH and LH levels, can result in DNA damage. These studies have also reported that the administration of FSH can reduce DNA damage in men with iOAT $[55,56]$. The FSH mechanism of action in reducing DNA damage, probably correlates with its anti-apoptotic and maturation promoting effects on Sertoli and germ cells. So, suppressing FSH can increase apoptotic DNA fragmentation [55, 57]. In addition, the role of FSH in sperm maturation is related to the replacement of histones with protamines during spermiogenesis [56]. Therefore, it seems that letrozole along with the increase of FSH could improve chromatin integrity through the proper replacement of histones with protamines. Similar to previous studies [52, 58], we observed a strong correlation between the percentage of sperm CMA3 positivity and DNA fragmentation (sperm TUNEL positivity). Such a degree of strong correlation in this study $(\mathrm{r}=+0.832, P<0.001)$ was probably related to the inclusion of a specific population of men with iOAT in this study.

A notable result of this study was achieving four spontaneous pregnancies (20\%) following letrozole treatment, which was consistent with the previous report [19].

In parallel with aromatase efficiency, letrozole efficiency was believed to be affected by numerous factors, including aromatase polymorphisms [59] and BMI [41]. The former was not considered in our study, but the comparison of pre- and post-treatment values of BMI and its correlation with letrozole efficiency in improving sperm parameters and hormonal balance were investigated. There was no significant difference in the BMI value before and after the letrozole treatment. Also, no significant correlation was observed between the baseline BMI and improvement in sperm parameters and hormonal balance following letrozole administration. Similar to

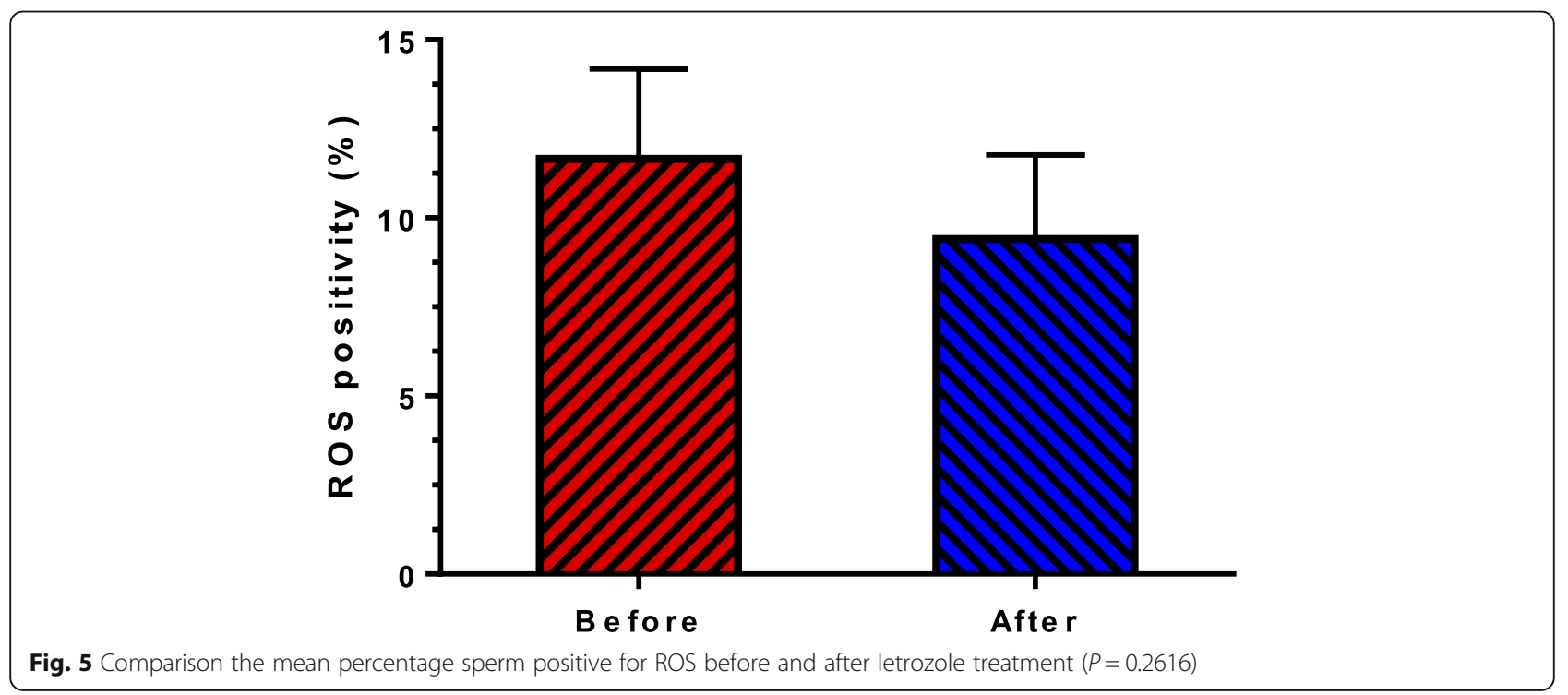


previous studies $[18,41]$, our results showed that baseline BMI cannot predict the results of letrozole administration in improvement of spermatogenesis.

In our study, only five patients reported decreased libido during the treatment. This was probably related to lower estrogen levels in these individuals. Appropriate levels of testosterone and estradiol and their proper ratio are required for libido [60]. The effect of estradiol on libido is related to testosterone levels. Studies have shown that in men with low testosterone levels, estradiol administration can increase sexual desire. Reversely, libido decreases after the estradiol treatment in men with normal testosterone levels [61-63]. Therefore, it seems that letrozole administration in iOAT men with low testosterone levels can decrease libido through the reduction of estradiol.

One of the limitations of this study, similar to other research in this field $[16,18,19]$, was the low number of patients studied, due to the low number of eligible patients to participate in this research. Also, the lack of control group in this research is due to the unwillingness of normal men to participate in research, which is one of the main challenges of human studies.

\section{Conclusion}

The results of this study showed that letrozole treatment in iOAT patients with $\mathrm{T}: \mathrm{E}_{2}$ ratio $\leq 10$ can increase testosterone level, decrease estradiol level and improve $\mathrm{T}: \mathrm{E}_{2}$ ratio $(1600 \%)$ as well as hormonal balance, which regulate male reproductive functions. In addition, sperm concentration, sperm motility and sperm morphology improved 260, 61 and 240\%, respectively. Furthermore, this study showed, for the first time, the degrees of protamine deficiency and DNA fragmentation were significantly reduced after treatment with letrozole. Finally, a notable result of this study was achieving four spontaneous pregnancies (20\%) following letrozole treatment. Based on the results of this study, letrozole treatment can be considered as an effective treatment for iOAT patients with $\mathrm{T}: \mathrm{E}_{2}$ ratio $\leq 10$.

\begin{abstract}
Abbreviations
BMI: Body mass index; iOAT: Oligo/astheno/teratozoospermia; T: Testosterone; $\mathrm{E}_{2}$ : Estradiol; TUNEL: Terminal deoxynucleotidyl transferasemediated fluorescein-dUTP nick end labeling; CMA3: Chromomycin A3; ROS: Reactive oxygen species; DCFH-DA: 2', 7'-dichlorodihydrofluorescein diacetate; FSH: Follicle-stimulating hormone; LH: Luteinizing hormone; WHO: World Health Organization; TdT: Terminal deoxynucleotidyl transferase; SEM: Standard Error of Mean
\end{abstract}

\section{Acknowledgements}

We would like to thank Dr. Tavalaie, Dr. R. Mohammadian and Dr. D. Mansori for their valuable cooperation in this research. In addition, we thank the Laboratory staff of anatomy department, central laboratory, paramedical science department of Shiraz University of Medical Sciences and Royan Institute for Biotechnology in Isfahan.

Ethical approval and consent to participate

This study was approved by the Ethical Board of Shiraz University of Medical Sciences (IR.SUMS.REC.1397.273).

\section{Authors' contributions}

The study was designed by MHN who also supported and supervised the writing of the manuscript. The procedure, data collection was carried out L. K under supervision of S.B. S. Z was involved in requirement of participant, clinical investigations and drug administration. The authors read and approved the final manuscipt.

\section{Funding}

The study was funded by vice chancellor of research affairs, Shiraz University of Medical Sciences. This article is extracted from the Ph.D. thesis results of Leila Kooshesh (Academic Grant Number 1396-01-01-15049).

\section{Availability of data and materials}

The primary data for this study is available from the authors upon direct request.

\section{Consent for publication}

Not applicable.

\section{Competing interests}

The authors declare that they have no competing interests.

\section{Author details}

'Department of Anatomy, Shiraz University of Medical Sciences, Shiraz, Iran. ${ }^{2}$ Department of Urology, Shiraz University of Medical Sciences, Shiraz, Iran. ${ }^{3}$ Department of Reproductive Biotechnology, Reproductive Biomedicine Research Centre, Royan Institute for Biotechnology, ACECR, Isfahan, Iran. ${ }^{4}$ Isfahan Fertility and Infertility Centre, Isfahan, Iran.

Received: 6 February 2020 Accepted: 13 April 2020

Published online: 13 May 2020

\section{References}

1. Wei T-C, Huang WJ, Lin AT, Chen K-K. The role of hormones on semen parameters in patients with idiopathic or varicocele-related oligoasthenoteratozoospermia (OAT) syndrome. J Chin Med Assoc. 2013;76(11):624-8.

2. Bracke A, Peeters K, Punjabi U, Hoogewijs D, Dewilde S. A search for molecular mechanisms underlying male idiopathic infertility. Reprod BioMed Online. 2018;36(3):327-39.

3. Kothandaraman N, Agarwal A, Abu-Elmagd M, Al-Qahtani MH. Pathogenic landscape of idiopathic male infertility: new insight towards its regulatory networks. NPJ Genomic Med. 2016;1:16023.

4. Eskenazi B, Wyrobek AJ, Sloter E, Kidd S, Moore L, Young S, et al. The association of age and semen quality in healthy men. Hum Reprod. 2003; 18(2):447-54.

5. Elzanaty S, Richthoff J, Malm J, Giwercman A. The impact of epididymal and accessory sex gland function on sperm motility. Hum Reprod. 2002;17(11): 2904-11.

6. Carpino A, Sisci D, Aquila S, Salerno M, Siciliano L, Sessa M, et al. Adnexal gland secretion markers in unexplained asthenozoospermia. Arch Androl. 1994;32(1):37-43.

7. Videau SP, Vivas JC, Salazar N. IgA antibodies to chlamydia trachomatis and seminal parameters in asymptomatic infertile males. Arch Androl. 2001;46(3):189-95.

8. Cavallini G. Male idiopathic oligoasthenoteratozoospermia. Asian J Androl. 2006;8(2):143-57.

9. Gorpinchenko I, Nikitin O, Banyra O, Shulyak A. The influence of direct mobile phone radiation on sperm quality. Cen Eur J Urol. 2014:67(1):65.

10. Caroppo E, Niederberger C, Vizziello GM, D'Amato G. Recombinant human follicle-stimulating hormone as a pretreatment for idiopathic oligoasthenoteratozoospermic patients undergoing intracytoplasmic sperm injection. Fertil Steril. 2003;80(6):1398-403.

11. Garg H, Kumar R. Empirical drug therapy for idiopathic male infertility: what is the new evidence? Urology. 2015;86(6):1065-75.

12. Kumar R, Gautam G, Gupta NP. Drug therapy for idiopathic male infertility: rationale versus evidence. J Urol. 2006;176(4):1307-12.

13. Madhukar D, Rajender S. Hormonal treatment of male infertility: promises and pitfalls. J Androl. 2009;30(2):95-112.

14. Pavlovich CP, King P, Goldstein M, Schlegel PN. Evidence of a treatable endocrinopathy in infertile men. J Urol. 2001;165(3):837-41. 
15. Başar MM, Tuğlu D. Aromatase inhibitors in infertile patients: effects on seminal parameters, serum and seminal plasma testosterone levels, and estradiol levels during short-term follow-up. Turkish J Med Sci. 2009;39(4):519-24.

16. Bibancos M, Cavagnoli M, Bonetti T, Semaco E, Motta E, Serafini PC. Letrozole therapy for obstructive Azoospermic men before in vitro fertilization (IVF) treatment with percutaneous Epididymal sperm aspiration. JBRA Assist Reprod. 2015;19(4):230-4.

17. Cavallini G, Beretta G, Biagiotti G. Preliminary study of letrozole use for improving spermatogenesis in non-obstructive azoospermia patients with normal serum FSH. Asian J Androl. 2011;13(6):895.

18. Cavallini G, Biagiotti G, Bolzon E. Multivariate analysis to predict letrozole efficacy in improving sperm count of non-obstructive azoospermic and cryptozoospermic patients: a pilot study. Asian J Androl. 2013;15(6):806.

19. Saylam B, Efesoy O, Çayan S. The effect of aromatase inhibitor letrozole on body mass index, serum hormones, and sperm parameters in infertile men. Fertil Steril. 2011;95(2):809-11.

20. Goswami S, Das T, Chattopadhyay R, Sawhney V, Kumar J, Chaudhury K, et al. A randomized single-blind controlled trial of letrozole as a low-cost IVF protocol in women with poor ovarian response: a preliminary report. Hum Reprod. 2004;19(9):2031-5.

21. Al-Fozan H, Al-Khadouri M, Tan SL, Tulandi T. A randomized trial of letrozole versus clomiphene citrate in women undergoing superovulation. Fertil Steril. 2004;82(6):1561-3.

22. Diamond MP, Legro RS, Coutifaris C, Alvero R, Robinson RD, Casson P, et al. Letrozole, gonadotropin, or clomiphene for unexplained infertility. N Engl J Med. 2015;373(13):1230-40.

23. Bhatnagar AS. The discovery and mechanism of action of letrozole. Breast Cancer Res Treat. 2007;105(1):7-17.

24. Santen RJ. Feedback control of luteinizing hormone and follicle-stimulating hormone secretion by testosterone and estradiol in men: physiologic and clinical implications. Clin Biochem. 1981;14(5):243-51.

25. Benchaib M, Braun V, Lornage J, Hadj S, Salle B, Lejeune H, et al. Sperm DNA fragmentation decreases the pregnancy rate in an assisted reproductive technique. Hum Reprod. 2003;18(5):1023-8.

26. Carrell D, Liu L, Peterson C, Jones K, Hatasaka H, Erickson L, et al. Sperm DNA fragmentation is increased in couples with unexplained recurrent pregnancy loss. Arch Androl. 2003;49(1):49-55.

27. Coughlan C, Clarke H, Cutting R, Saxton J, Waite S, Ledger W, et al. Sperm DNA fragmentation, recurrent implantation failure and recurrent miscarriage. Asian J Androl. 2015;17(4):681.

28. García-Ferreyra J. Sperm DNA fragmentation and its relation with fertility. In: Bin Wu, editor. New discoveries in embryology. London: InTechOpen publisher; 2015;3-17; https://doi.org/10.5772/60825.

29. Huang C-C, Lin DP-C, Tsao H-M, Cheng T-C, Liu C-H, Lee M-S. Sperm DNA fragmentation negatively correlates with velocity and fertilization rates but might not affect pregnancy rates. Fertil Steril. 2005;84(1):130-40.

30. Robinson L, Gallos ID, Conner SJ, Rajkhowa M, Miller D, Lewis S, et al. The effect of sperm DNA fragmentation on miscarriage rates: a systematic review and meta-analysis. Hum Reprod. 2012:27(10):2908-17.

31. Sedó CA, Bilinski M, Lorenzi D, Uriondo H, Noblía F, Longobucco V, et al. Effect of sperm DNA fragmentation on embryo development: clinical and biological aspects. JBRA Assist Reprod. 2017;21(4):343.

32. Xue L-T, Wang R-X, He B, Mo W-Y, Huang L, Wang S-K, et al. Effect of sperm DNA fragmentation on clinical outcomes for Chinese couples undergoing in vitro fertilization or intracytoplasmic sperm injection. J Int Med Res. 2016; 44(6):1283-91.

33. Zheng W-W, Song G, Wang Q-L, Liu S-W, Zhu X-L, Deng S-M, et al. Sperm DNA damage has a negative effect on early embryonic development following in vitro fertilization. Asian J Androl. 2018;20(1):75.

34. Lu J-C, Huang Y-F, Lü N-Q. WHO Laboratory manual for the examination and processing of human semen: its applicability to andrology laboratories in China. Zhonghua nan ke xue=. Natl J Androl. 2010;16(10):867-71.

35. Nasr-Esfahani MH, Razavi S, Mardani M. Andrology: relation between different human sperm nuclear maturity tests and in vitro fertilization. J Assist Reprod Genet. 2001;18(4):221-7.

36. Nasr-Esfahani MH, Aboutorabi R, Razavi S. Credibility of chromomycin A3 staining in prediction of fertility. Int J Fertil Steril. 2009;3(1);5-10.

37. Muratori M, Tamburrino L, Marchiani S, Guido C, Forti G, Baldi E. Critical aspects of detection of sperm DNA fragmentation by TUNEL/flow cytometry. Syst Biol Reprod Med. 2010;56(4):277-85.
38. Kiani-Esfahani A, Tavalaee M, Deemeh MR, Hamiditabar M, Nasr-Esfahani $\mathrm{MH}$. DHR123: an alternative probe for assessment of ROS in human spermatozoa. Syst Biol Reprod Med. 2012;58(3):168-74.

39. Pavelescu L. On reactive oxygen species measurement in living systems. J Med Life. 2015;8(Spec Issue):38

40. Mahfouz R, Sharma R, Lackner J, Aziz N, Agarwal A. Evaluation of chemiluminescence and flow cytometry as tools in assessing production of hydrogen peroxide and superoxide anion in human spermatozoa. Fertil Steril. 2009;92(2):819-27.

41. Schlegel PN. Aromatase inhibitors for male infertility. Fertil Steril. 2012;98(6):1359-62

42. Brodie AM. Aromatase inhibition and its pharmacologic implications. Biochem Pharmacol. 1985:34(18):3213-9.

43. Bharti S, Misro M, Rai U. Clomiphene citrate potentiates the adverse effects of estrogen on rat testis and down-regulates the expression of steroidogenic enzyme genes. Fertil steril. 2013;99(1):140-8 e5.

44. Jayasena CN, Radia UK, Fiqueiredo M, Revill LF, Dimakopoulou A, Osagie M, et al. Reduced testicular Steroidogenesis and increased semen oxidative stress in male partners as novel markers of recurrent miscarriage. Clin Chem. 2019;65(1):161-9.

45. Darbandi M, Darbandi S, Agarwal A, Sengupta P, Durairajanayagam D, Henkel $R$, et al. Reactive oxygen species and male reproductive hormones. Reprod Biol Endocrinol. 2018;16(1):1-14.

46. Aitken RJ, Roman SD. Antioxidant systems and oxidative stress in the testes. Oxidative Med Cell Longev. 2008;1(1):15-24.

47. Agarwal A, Said TM. Role of sperm chromatin abnormalities and DNA damage in male infertility. Hum Reprod Update. 2003;9(4):331-45.

48. Tavalaei M, Nasresfahani MH, Deymeh M. Etiology and evaluation of sperm chromatin anomalies; 2008.

49. Panner Selvam MK, Agarwal A. A systematic review on sperm DNA fragmentation in male factor infertility: laboratory assessment. Arab J Urol. 2018;16(1):65-76.

50. González-Marín C, Gosálvez J, Roy R. Types, causes, detection and repair of DNA fragmentation in animal and human sperm cells. Int J Mol Sci. 2012; 13(11):14026-52.

51. Andrabi S. Mammalian sperm chromatin structure and assessment of DNA fragmentation. J Assist Reprod Genet. 2007:24(12):561-9.

52. Nili HA, Mozdarani $H$, Aleyasin A. Correlation of sperm DNA damage with protamine deficiency in Iranian subfertile men. Reprod BioMed Online. 2009; 18(4):479-85.

53. Roca J. Topoisomerase II: a fitted mechanism for the chromatin landscape. Nucleic Acids Res. 2008;37(3):721-30.

54. Bakshi R, Galande S, Bali P, Dighe R, Muniyappa K. Developmental and hormonal regulation of type II DNA topoisomerase in rat testis. J Mol Endocrinol. 2001;26(3):193-206.

55. Baldi E, Muratori M. Effects of FSH on sperm DNA fragmentation: review of clinical studies and possible mechanisms of action. Front Endocrinol. 2018;9:734.

56. Colacurci N, De Leo V, Ruvolo G, Piomboni P, Caprio F, Pivonello R, et al. Recombinant FSH improves sperm DNA damage in male infertility: a phase II clinical trial. Front Endocrinol. 2018:9:383.

57. Ruvolo G, Fornaro F, Bosco L, Colacurci N, Cittadini E. R-FSH administration in idiopathic oligoasthenoteratozoospermic patients (iOAT) reduces the apoptotic rate in sperm cells. Fertil Steril. 2009;92(3):S72-S3.

58. Razavi S, Nasr-Esfahani M, Deemeh M, Shayesteh M, Tavalaee M. Evaluation of zeta and HA-binding methods for selection of spermatozoa with normal morphology, protamine content and DNA integrity. Andrologia. 2010;42(1):13-9.

59. Hammoud AO, Griffin J, Meikle AW, Gibson M, Peterson CM, Carrell DT. Association of aromatase (TTAAn) repeat polymorphism length and the relationship between obesity and decreased sperm concentration. Hum Reprod. 2010;25(12):3146-51.

60. Schulster M, Bernie AM, Ramasamy $R$. The role of estradiol in male reproductive function. Asian J Androl. 2016;18(3):435

61. Wibowo E, Schellhammer P, Wassersug RJ. Role of estrogen in normal male function: clinical implications for patients with prostate cancer on androgen deprivation therapy. J Urol. 2011:185(1):17-23.

62. Davidson JM, Allinson PA. Effects of estrogen on the sexual behavior of male rats. Endocrinology. 1969;84(6):1365-72.

63. Bancroft J, Tennent G, Loucas K, Cass J. The control of deviant sexual behaviour by drugs: I. Behavioural changes following oestrogens and antiandrogens. Br J Psychiatry. 1974;125(586):310-5.

\section{Publisher's Note}

Springer Nature remains neutral with regard to jurisdictional claims in published maps and institutional affiliations. 